\title{
Theoretical Study of Single Phase Heat Transfer in a Helically Coiled Tube of Small Diameter
}

\author{
Ashish Kumar Pandey, P. K. Mishra, and K. K. Srivastava
}

\begin{abstract}
In recent years, heat transfer enhancement techniques have become one of the main thermal research fields. Helically coiled configuration is more preferable due to their large heat transfer area in a small space, higher heat transfer coefficients and longer operating life. In this research article, theoretical analysis has been conducted to investigate the heat transfer characteristics of single phase laminar flow in a helically coiled tube of small diameter. This work deals with analysis of the coiled tube with different correlations developed for specific conditions by previous researchers. The present analysis follows similar trend for heat transfer coefficient as reported by previous authors. Water is more feasible than nitrobenzene because of its higher heat transfer coefficient.
\end{abstract}

Index Terms-Helical coil, heat exchangers, heat transfer, laminar flow.

\section{INTRODUCTION}

Helically coiled heat exchangers have important applications such as heat recovery systems, power generations, refrigeration, chemical reactors, nuclear reactors etc. The helically coiled tube exchangers have distinct advantages such as condensing, boiling, preheating, cooling, heat recovery and basic heat exchange. Because of its compact structure and high heat transfer coefficient, numerous studies have been conducted to investigate the heat transfer and flow characteristics inside coiled tubes. In several literatures it has been found that heat transfer rates in helical coils are higher as compared to those in straight tubes. This phenomenon is more beneficial especially in laminar flow regime.

Flow through curved pipe was first mathematically researched [1], [2]. The steady motion of incompressible fluid flowing through fully developed laminar flow in a toroidal pipe was considered in the analysis and reported that flow due to curvature depends on dimensionless number termed as Dean number, defined as the ratio of centrifugal force to inertial force. Effects of tube and coil diameters on flow boiling heat transfer coefficients inside a helically coiled tube (the tube diameters ranges from 1.1 to $2.8 \mathrm{~mm}$ ) experimentally investigated. It was observed that decreasing the tube diameter and the coil diameter improves the heat transfer coefficient with up to $63 \%$ and $150 \%$ enhancement respectively. A new correlation for the boiling heat transfer

Manuscript received October 14, 2014; revised January 2, 2015.

The authors are with Department of Chemical Engineering \& Technology, Indian Institute of Technology (Banaras Hindu University), Varanasi, India (e-mail: akp0510@gmail.com). coefficient based on nucleate boiling suppression and convective boiling enhancement factors was also developed [3]. Pressure drop of single phase fluid for laminar flow regime inside a vertical helically coiled tube with a curvature ratio of 0.012 experimentally studied. Experimental results showed good agreement with numerical values [4]. Pressure drop characteristics of nanofluid flow inside vertical helically coiled tubes of $15.6 \mathrm{~mm}$ internal diameter for isothermal boundary conditions in the laminar flow regime experimentally investigated [5]. It was found that increasing coil to tube diameter ratio pressure drop decreased. Simultaneous utilization of helical coils and nanofluids had a high capability to increase the pressure drop.

Thermodynamic analyses and heat transfer study in a helically coiled heat exchanger of $9 \mathrm{~mm}$ inner diameter using different types of nanofluids were investigated. The increment of particle volume fraction and volume flow rate of nanofluids enhanced heat transfer coefficient [6]. Heat transfer and friction factor characteristics of $\mathrm{CuO}$-water nanofluid in the fully developed laminar region with constant heat flux in plain and dimpled tube of $4.85 \mathrm{~mm}$ diameter investigated experimentally [7]. The mechanism of heat transfer enhancement obtained with nanofluids was due to particle migration from the core of fluid flow to tube wall.

A comparative study of the heat transfer rates between a straight tube heat exchanger and a helically coiled heat exchanger was experimentally performed. Helical coiled heat exchangers had higher heat transfer coefficients compared to that of similar dimension straight tube heat exchanger [8].

Steady state natural convection of air through horizontally coiled tubes was experimentally investigated. The experiments were conducted for different coil geometries in the range of heat flux $500-5000 \mathrm{~W} / \mathrm{m}^{2}$. A decrease of the heat transfer coefficient was reported in the laminar regime [9]. Convective heat transfer in helical coils for laminar flow was studied and correlations of friction factor and Nusselt number $(\mathrm{Nu})$ were suggested for both constant wall temperature and constant wall heat flux [10]. Laminar forced convection and entropy generation in a helical coil with curvature ratio of 0.1104 in the range of Re 1000-7500 for constant wall heat flux numerically investigated. The relationship between entropy generation and heat flux was dependent on Reynolds number [11].

Performance analysis of helically coiled heat exchangers with circular minichannels of $1 \mathrm{~mm}$ inner diameter was also studied [12]. Numerical simulation was performed calculating heat transfer rate and pressure drop for performance analysis of helically coiled exchangers. The heat transfer rate and pressure drop in low mass velocity from simulation showed good agreement with experimental results 
with accuracy of $15 \%$.

The three-dimensional parabolic flows were applied to predict the velocity and temperature fields in numerical study of helically coiled pipes for laminar flow. Good agreements of results were obtained in comparison with the experimental data [13].

A computational fluid dynamics (CFD) analysis was considered to investigate the effects of thermally dependent viscosity and non-Newtonian flows on heat transfer and pressure drop for laminar flow in a double-pipe helical heat exchanger. Thermally dependent viscosities had very less effect on the Nusselt number and significant effects on the pressure drop for Newtonian fluids [14].

Fluid flow and heat transfer through a curved tube was reviewed [15]-[18]. The latest review of flow and heat transfer characteristics is also provided [19]. It has been found that only a few studies have been done on small sized helical tubes. In the present study, theoretical study has been carried out to study single phase heat transfer through a vertical helically coiled tube of $0.72 \mathrm{~mm}$ inner diameter for laminar flow.

\section{GEOMETRIC CONFIGURATIONS}

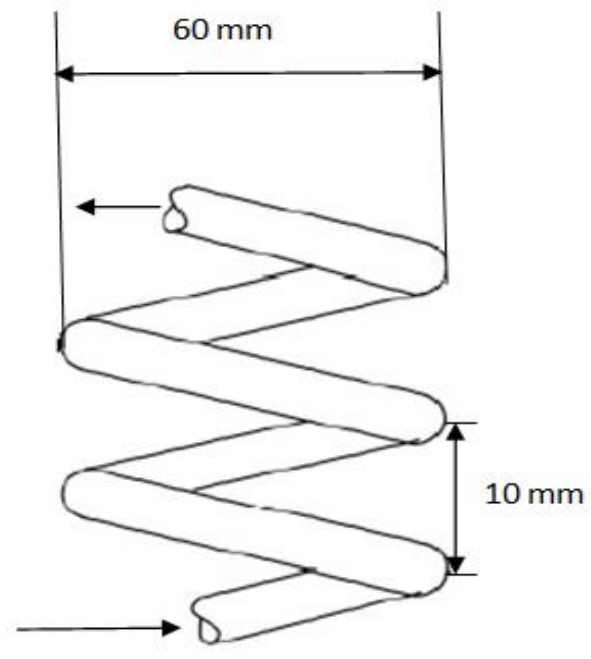

Fig. 1. Helically coiled tube.

TABLE I: FLUID PROPERTIES

\begin{tabular}{|c|c|c|c|c|}
\hline Fluid & $\begin{array}{c}\text { Density } \\
\rho \\
\left(\mathrm{Kgm}^{-3}\right)\end{array}$ & $\begin{array}{c}\text { Viscosity } \\
\mu \\
\left({\left.\mathrm{N} . \mathrm{sm}^{-2}\right)}^{-2}\right.\end{array}$ & $\begin{array}{c}\text { Heat } \\
\text { Capacity } \\
c_{p} \\
\left(\mathrm{~J} \mathrm{Kg}^{-1} \mathrm{~K}^{-1}\right)\end{array}$ & $\begin{array}{c}\text { Thermal } \\
\text { Conductivity } \\
\kappa \\
\left(\mathrm{W} \mathrm{m}^{-1} \mathrm{~K}^{-1}\right)\end{array}$ \\
\hline Water & 1000 & 0.001 & 4170 & 0.58 \\
\hline Nitrobenzene & 1200 & 0.002 & 1400 & 0.16 \\
\hline
\end{tabular}

Geometrical parameters are same as presented in [4]. Fig. 1 represents a helical coil of $0.72 \mathrm{~mm}$ inner diameter (d) and $1.5 \mathrm{~mm}$ outer diameter with 3 turns, coil diameter and the coil pitch are $60 \mathrm{~mm}$ and $10 \mathrm{~mm}$ respectively. Coiled tube has a length of $565 \mathrm{~mm}$. Analysis is considered to study the heat transfer characteristics of working fluids over the length of coiled tube in the range of Reynolds number (Re) 555 to 2038. Water and nitrobenzene are used as working fluid and their properties are predicted in table 1 . The Dean number $(D e)$ is varied from 60 to 222 for water and 33 to 103 for nitrobenzene respectively. Water is considered as reference fluid in this study.

\section{THEORETICAL ANALYSIS}

Limited correlations of Nusselt number are available for small sized coiled tube for laminar flow. Following correlations at specified conditions are applicable for present analysis.

Mori and Nakayama [20] for $D e<2000$

$$
N u=N u_{s}(0.1979) D e^{0.5}
$$

Nusselt number for fully developed region in straight tube for constant heat flux

$$
N u_{s}=4.36
$$

Dravid et al. [21] for $50<D e<2000$ and $5<\operatorname{Pr}<175$

$$
N u=(0.65 \sqrt{D e}+0.76) \operatorname{Pr}^{0.175}
$$

In this study both correlations Mori and Nakayama [20] and Dravid et al. [21] are applicable for calculation of Nusselt number for water. But in the case of nitrobenzene only Mori and Nakayama [20] is suitable because of its Dean number.

Heat transfer coefficient $(h)$ can be calculate as

$$
h=\frac{N u \times \kappa}{d}
$$

\section{RESULTS AND DISCUSSIONS}

Theoretical analysis is carried out for heat transfer coefficient inside a helically coiled tube for laminar flow. Prandtl number $(\mathrm{Pr})$ for water and nitrobenzene are 7.2 and 17.68 respectively. Fully developed region and constant heat flux conditions are considered. Selected correlations of Nusselt number from literature fulfill the conditional requirements of present analysis.

Effect of Dean number on heat transfer coefficient for both working fluids is predicted in Fig. 2. It is clear from figure that heat transfer coefficient significantly increases with Dean number. In laminar regime due to the curvature of the tubes centrifugal force is generated. This centrifugal force developed secondary flow. Due to effect of secondary flow 
there is higher heat transfer coefficient. The heat transfer enhancement is more in vertical position than in horizontal due to rapid developments of secondary flow. The present analysis also follows similar trend for heat transfer coefficient as reported by previous authors.

Heat transfer coefficient from Dravid et al. correlation is greater than that of Mori and Nakayama's correlation in case of water. The difference between heat transfer coefficient obtained from above correlations is about $13.6 \%$. Heat transfer coefficient of water is $80 \%$ greater than nitrobenzene. Maximum heat transfer coefficient for nitrobenzene is $1946 \mathrm{Wm}^{-2} \mathrm{~K}^{-1}$ at $D e=103$ which is lesser than heat transfer coefficient of water $5043 \mathrm{Wm}^{-2} \mathrm{~K}^{-1}$ at $D e=60$.

Nitrobenzene is more viscous than water but its thermal properties are lower than water, which is responsible for lower heat transfer coefficient. From thermal point of view water is more feasible than nitrobenzene because its offer better heat transfer coefficient than nitrobenzene.

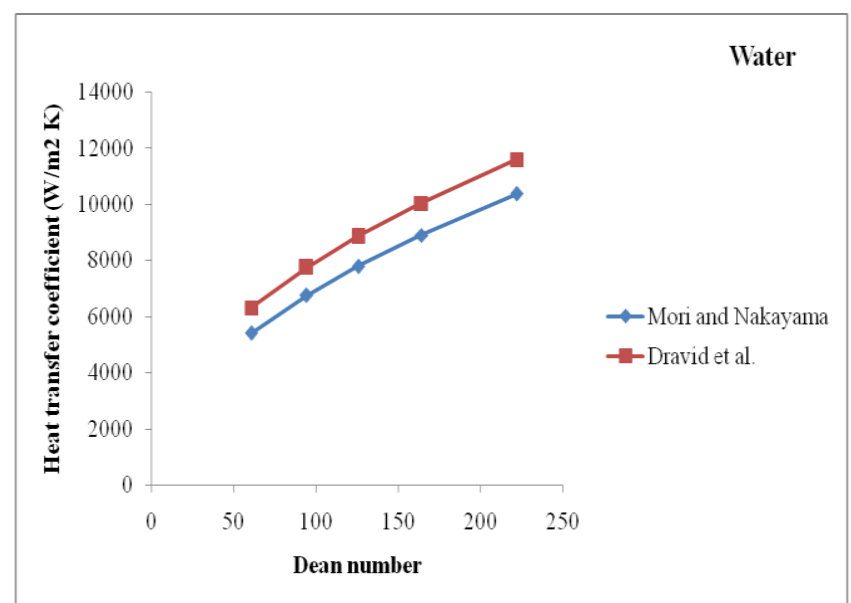

(a) Water

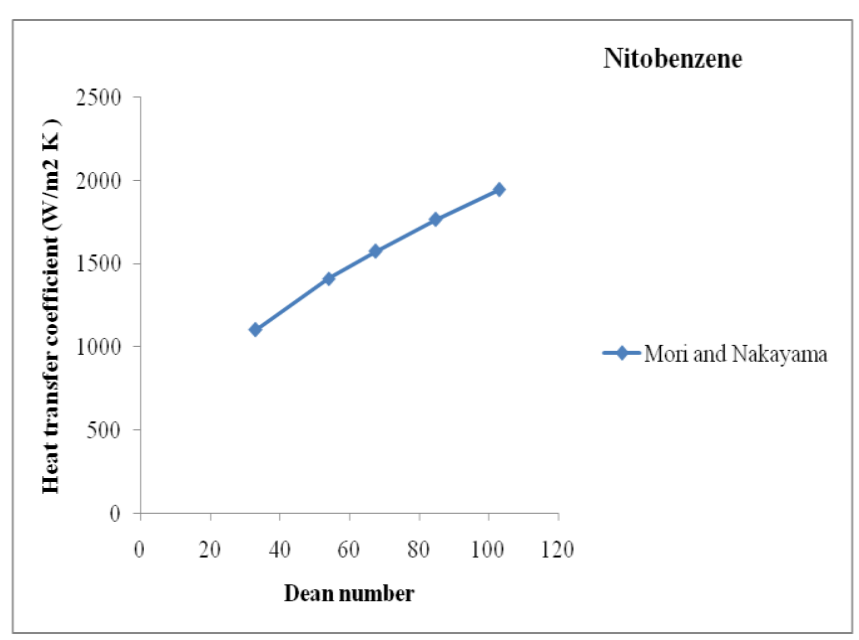

(b)Nitrobenzene

Fig. 2. Effect of Dean number on heat transfer coefficient (a) Water (b) Nitrobenzene.

\section{CONCLUSIONS}

In the present study, the single phase heat transfer coefficient in a helically coiled tube of small diameter for laminar flow analyzed theoretically. The following conclusions are drawn from this study:
- Heat transfer coefficient increases with Dean number.

- The present analysis follows similar trend for heat transfer coefficient as reported by previous authors.

- Heat transfer coefficient from Dravid et al. correlation is $13.6 \%$ greater than that of Mori and Nakayama's correlation for water.

- Heat transfer coefficient of water is $80 \%$ greater than nitrobenzene.

- Thermal properties of nitrobenzene are responsible for lower heat transfer coefficient.

- Water is more feasible than nitrobenzene because of its higher heat transfer coefficient.

\section{REFERENCES}

[1] W. R. Dean, "Note on the motion of fluid in a curved pipe," Philosophical Magazine, vol. 20, pp. 208-223, 1927.

[2] W. R. Dean, "The stream line motion of fluid in a curved pipe," Philosophical Magazine, vol. 5, pp. 208-223, 1927.

[3] A. M. Elsayed, R. A. Dadah, S. Mahmoud, and A. Rezk, "Investigation of flow boiling heat transfer inside small diameter helically coiled tubes," International Journal of Refrigeration, vol. 35, pp. 2179-2187, 2012.

[4] A. K. Pandey, P. K. Mishra, and K. K. Srivastava, "Experimental investigation of pressure drop inside a vertical helically coiled tube of curvature ratio= 0.012," International Journal of Engineering \& Science Research, vol. 4, pp. 398-401, 2014.

[5] M. F. Pakdaman, M. A. A. Behabadi, and P. Razi, "A empirical study on the pressure drop characteristics of nanofluid flow inside helically coiled tubes," International Journal of Thermal Science, vol. 65, pp. 206-213, 2013.

[6] M. A. Khairul, R. Saidur, M. M. Rahman, M. A. Alim, A. Hossain, and Z. Abdin, "Heat transfer and thermodynamic analysis of helically coiled heat exchanger using different types of nanofluids," International Journal of Heat and Mass Transfer, vol. 67, pp. 398-403, 2013.

[7] S. Suresh, M. Chandrasekar, and P. Selvakumar, "Experimental studies on heat transfer and friction factor characteristics of Cuo/water nanofluid under laminar flow in a helically dimpled tube," Heat and Mass Transfer, vol. 48, pp. 683-694, 2012.

[8] D. G. Prabhanjan, G. S. V. Raghavan, and T. J. Renni, "comparison of heat transfer rates between a straight tube heat exchanger and a helically coiled heat exchanger," International Communication of Heat and Mass Transfer, vol. 29, pp. 185-191, 2002.

[9] M. E. Ali, "Laminar natural convection from constant heat flux helical coiled tubes," International Journal of Heat and Mass Transfer, vol. 31, pp. $175-2182,1998$

[10] R. L. Manlapaz and S. W. Churchill, "Fully developed laminar convection from a helically coil," Chemical Engineering Communication, vol. 9, pp. 185-200, 1982.

[11] T. H. Ko, "Numerical Investigation of Laminar forced convection and entropy generation in a helical coil with constant wall heat flux," Numerical Heat Transfer Part A, vol. 49, pp. 257-278, 2006.

[12] J. W. Kim, Y. B. Im and J. S. Kim, "A study on performance analysis of helically coiled evaporator with circular mini channels," Journal of Mechanical Science and Technology, vol. 20, pp. 1059-1067, 2006.

[13] S. V. Patankar, V. S. Pratap, and D. B. Spalding, "Prediction of laminar flow and heat transfer in helically coiled pipes", Journal of Fluid Mechanics, vol. 62, pp.539-551, 1974.

[14] T. J. Rennie and G. S. V. Raghavan, "Thermally dependent viscosity and non Newtonian flow in a double pipe helical heat exchanger," Applied Thermal Engineering, vol. 27, pp. 862-868, 2007.

[15] S. A. Berger, L. Talbot, and L. S. Yao, "Flow in curved pipes," Annual Review Fluid Mechanics, vol. 15, pp. 461-512, 1983.

[16] R. K. Shah and S. D. Joshi, "Convective heat transfer in curved ducts," Handbook of Single-Phase Convective Heat Transfer, S. Kakac, R. K. Shah, and W. Hung Eds., Wiley Interscience, New York, 1987, Chapter 3.

[17] P. Naphon and S. Wongwises, "A review of flow and heat transfer characteristics in curved tubes," Renewable and Sustainable Energy Reviews, vol.10, pp. 463-490, 2006.

[18] S. S. Pawar, V. K. Sunnapwar, and B. A. Mujawar, "A critical review of heat transfer through helical coils of circular cross section", Journal of Scientific \& Industrial Research, vol. 70, pp. 835-843, 2011. 
[19] A. K. Pandey, P. K. Mishra, and K. K. Srivastava, "A critical review on fluid flow and heat transfer in circular helically coiled tube heat exchanger for laminar flow," International Journal of Engineering \& Science Research, vol. 4, pp. 436-445, 2014.

[20] Y. Mori and W. Nakayama, "Study on forced convective heat transfer in curved tubes (1st report, laminar region)," International Journal of Heat and Mass Transfer, vol. 8, pp. 67-82, 1965.

[21] A. N. Dravid, K. A. Smith, E. W. Merrill, and P. L. T. Brain, "Effect of secondary fluid on laminar flow heat transfer in helically coiled tubes," AIChE Journal, vol. 17, pp. 1114-1122, 1971.

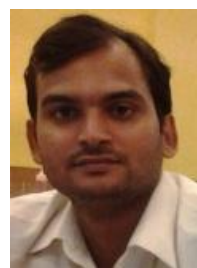

Ashish Kumar Pandey is a PhD student in Department of Chemical Engineering and Technology, Indian Institute of Technology Banaras Hindu University, Varanasi, India. He got his B.Tech degree in chemical engineering in 2009 from UPTU Lucknow, India. Also he received his M.Tech degree in chemical engineering from NIT Rourkela, India in 2011. His areas of interest include fluid flow and heat transfer in coiled tube, minichanne and microchannel, modeling and simulation etc. 